\title{
Prática profissional e metodologia assistencial dos enfermeiros em hospital filantrópico
}

\author{
Professional practice and asssitance methodology of nurses in a philantrropic hospital \\ Práctica profesional y metodología asistencial de enfermeros en hospital filantropico
}

\author{
Ana Carolina Floriano Moura', Cristiane Borges de Moura Rabêlo", \\ Maria do Rozário de Fátima Borges Sampaio"II \\ 'Hospital São Marcos. Teresina PI \\ "Faculdade Integral Diferencial. Teresina, PI \\ II'Universidade Federal do Piauí. Teresina, PI
}

Submissão: 13/03/2008

Aprovação: 3 1/07/2008

\section{RESUMO}

Este estudo objetivou identificar as atividades que caracterizam o fazer profissional dos enfermeiros a partir de sua prática, bem como conhecer e analisar a metodologia assistencial utilizada para sistematizar suas ações. Trata-se de uma pesQuisa com abordagem Qualitativa, de natureza descritiva, realizada com doze enfermeiros assistenciais de um hospital filantrópico na cidade de Teresina-PI. Utilizou-se para coleta de dados, roteiro de entrevista e técnica de diário de campo. Após análise temática das entrevistas, definiram-se três categorias: Fazer profissional do enfermeiro: fazer assistencial $x$ fazer administrativo; Metodologia assistencial: o conhecimento direcionando a prática; Sistematização da Assistência de Enfermagem (SAE) como metodologia. Os resultados da pesquisa ofereceram elementos importantes a serem repensados pelos enfermeiros Quanto a sua prática profissional e metodologia assistencial.

Descritores: Enfermagem; Prática profissional; Metodologia.

\section{ABSTRACT}

This study aimed at identifying the activities that characterize the nurse's professional performance as well as to know and to analyze the assistance methodology used to organize their actions. It is a research made through a Qualitative approach and descriptive study, with subjects composed by twelve assistance nurses from a philanthropic hospital in Teresina-PI. The data were collected by interviews and fieldwork. After the interview analysis, one defined the three categories: Nurse's professional performance; assistance methodology: knowledge leading practice; Nursing Assistance Systematization (NAS) as methodology. The search results offered important elements to be rethought by nurses about their professional practice and methodology care.

Descriptors: Nursing; Professional practice; Methodology.

\section{RESUMEN}

Este estudio objetivó identificar las actividades que caracterizan el hacer profesional de los enfermeros a partir de su práctica, bien como conocer y analizar la metodología asistencial utilizada para sistematizar sus acciones. Tratase de una pesQuisa de abordaje cualitativa, de natureza descritiva, realizada con doce enfermeros asistenciales de uno hospital filantropico en la ciudad de Teresina-PI. Utilizouse para coleta de dados guía de entrevista y técnica de diario de campo. Despúes de la análisis tematica de las entrevistas, definiranse tres categorias: hacer profesional de lo enfermero; hacer asistencial $x$ hacer administrativo; metodología asistencial: el conocimiento direcionado para la práctica; sistematización de la asistencia de enfermeria (SAE) como metodología. Los resultados de la pesQuisa ofreceran elemientos a sieren repensados por los enfermeros cuanto a su práctica profesional y metodología asistencial.

Descriptores: Enfermería; Práctica profesional; Metodología. 


\section{INTRODUÇÃO}

A Enfermagem pode ser descrita como profissão de ajuda, complexa e multifacetada, constituída por ampla variedade de elementos Que entram em sua composição e em sua prática. Um desses elementos é o cuidar, constructo teórico considerado central para a Enfermagem. Entretanto, os enfermeiros, ao longo da prática profissional, historicamente sobrecarregados com atividades envolvendo registros, anotações, relatórios e comunicações, têm utilizado grande parte de seu tempo em atividades burocráticas e na busca e documentação de informações, reservando a assistência de enfermagem ao cliente um papel secundário ${ }^{(1)}$.

Nesse contexto, considera-se a necessidade de uma metodologia de trabalho para oue o enfermeiro desenvolva um plano de cuidados de enfermagem pautado na assistência global ao paciente e no conhecimento técnico-científico pertinente ${ }^{(2)}$. O enfermeiro Que atua embasado numa metodologia de assistência assume postura ética e legal, consoante o que preconiza a Lei $n^{\circ} 7.498 / 86$, reforçada pela Resolução no 272/2002, do Conselho Federal de Enfermagem (COFEN), que determina a Sistematização da Assistência de Enfermagem (SAE).

A Sistematização da Assistência de Enfermagem (SAE) é método e estratégia de trabalho científico adeouado para a identificação das situações de saúde/doença. Subsidia ações de assistência de enfermagem Que possam contribuir para a promoção, prevenção, recuperação e reabilitação da saúde do indivíduo, família e comunidade. Possibilita, assim, a caracterização da prática profissional do enfermeiro e colabora com a definição do papel deste profissional de saúde ${ }^{(3)}$.

A assistência embasada em uma metodologia, ao buscar compreendê-la e vivenciá-la, fará com que se "desaprendam" alguns pontos Que já aprendidos, libertando conceitos, conhecimentos e práticas ultrapassadas e Que, no momento, não são mais úteis e, por conseguinte, possibilitará "reaprender" conhecimentos que enriquecerão a atuação do profissional ${ }^{(4)}$.

O interesse pela temática surgiu no $3^{\circ}$ período do Curso de Graduação em Enfermagem, ocasião em Que cursava a disciplina Fundamentação Teórica de Enfermagem, Quando pude conhecer as diversas teorias de enfermagem bem como o processo de enfermagem desenvolvido mediante várias metodologias assistenciais. Ao iniciar as atividades práticas em um estágio extracurricular em uma instituição filantrópica, na Qual hoje trabalho, tive oportunidade de observar Que a essência do ser enfermeiro, o cuidar, muitas vezes se perdia, devido à grande demanda de pacientes e à pouca Quantidade de enfermeiros para a assistência adequada à saúde.

A partir desse conhecimento, surgiram os seguintes Questionamentos: a) Que atividades são realizadas pelos enfermeiros em sua prática profissional? b) Que metodologia assistencial os enfermeiros utilizam para sistematizar as suas atividades? Estes Questionamentos culminaram com o estudo Que a eles buscou responder.

Este trabalho é bastante oportuno e relevante, principalmente no momento em Que se percebe insatisfação dos enfermeiros em seu trabalho cotidiano, o Que gera Questionamentos relacionados à posição na equipe de saúde, no modelo de saúde vigente e na sociedade em geral(5). É evidente, portanto, a necessidade de estudos
Que analisem o Que os enfermeiros estão executando em sua prática profissional, assim como a metodologia assistencial adotada para dimensionar as funções, proporcionando assim reflexões sobre a prática de que resulte ajuda para transformar e humanizar o exercício da Enfermagem.

\section{OBJETIVOS}

- Identificar as atividades Que caracterizam o fazer profissional dos enfermeiros a partir de sua prática;

- Conhecer a metodologia assistencial utilizada pelos enfermeiros para sistematizar suas ações em um hospital filantrópico;

- Analisar a metodologia assistencial utilizada pelos enfermeiros para sistematizar suas ações em um hospital filantrópico.

\section{METODOLOGIA}

Trata-se de uma pesQuisa de campo Que tem como objetivo não apenas uma aproximação com aQuilo Que se deseja conhecer ou estudar, mas também criar conhecimento, partindo da realidade presente no campo, além de descrever as características de uma determinada populaçãão).

Visando aprofundar a realidade, utilizou-se abordagem Qualitativa para o desenvolvimento da pesquisa. A pesquisa Qualitativa corresponde a um espaço mais profundo das relações, dos processos e dos fenômenos, por trabalhar com o universo de significados, motivos, crenças, valores, aspirações e atitudes, não podendo, portanto, ser reduzida à operacionalização de variáveis. Além disso, a pesquisa eualitativa é particularmente adęuada ao estudo da experiência humana sobre saúde, preocupação fundamental da ciência da Enfermagem ${ }^{(7)}$.

A pesquisa foi aprovada pelo Comitê de Ética em Pesquisa CEP da Instituição onde foi desenvolvido o estudo, e pelo Comitê de Ética em Pesquisa - CEP da Faculdade Integral Diferencial FACID. O cenário da pesquisa foi uma instituição filantrópica, centro de referência em oncologia, localizada na cidade de Teresina-Piauí. O universo do estudo constituiu-se de 44 enfermeiros que trabalham na referida instituição, em diversos setores (pronto-atendimento, centro cirúrgico, clínica médica, clínica cirúrgica, clínica pediátrica e unidade de terapia intensiva) e que estão diretamente envolvidos com atividades assistenciais. Para o desenvolvimento da pesquisa, respeitaram-se as diretrizes e normas regulamentadoras de pesquisa com seres humanos, da Resolução 196/96 do Conselho Nacional de Saúde ${ }^{(8)}$.

A amostra foi definida de forma aleatória e composta de 12 enfermeiros. Selecionaram-se os sujeitos da pesquisa mediante entrevista parcialmente estruturada, até se atingir o ponto de saturação das respostas. A saturação dos dados ocorre Quando as informações Que estão sendo compartilhadas com o pes\&uisador se tornam repetitivas, e a inclusão de outros participantes não resulta em idéias novas ${ }^{(9)}$.

No registro das informações, utilizou-se um diário de campo, onde se registraram percepções, Questionamentos e informações do pesquisador. Os dados coletados se submeteram à análise de conteúdo temática, numa tentativa de busca da compreensão dos significados no contexto da fala, objetivando ultrapassar o alcance meramente descritivo da mensagem, para atingir, mediante 
inferência, interpretação mais profunda, em Que a presença ou a freeüência de aparição pode significar alguma coisa para o objetivo escolhido ${ }^{(6)}$

\section{RESULTADOS E DISCUSSÃO}

\section{Perfil Sóciodemográfico dos Participantes do Estudo}

Após aplicação do Questionário sóciodemográfico contido no roteiro de entrevista, observou-se Que, dos enfermeiros entrevistados, a maioria era do sexo

feminino $(67 \%)$, solteiro $(67 \%)$; encontravam-se na faixa etária de 20 a 30 anos (83\%), todos católicos (100\%), naturais do Piauí (50\%); metade deles procedente do interior do Estado (50\%). Dos 12 participantes, 75\% possuíam de 3 meses a 4 anos de formação; a maioria, concluiu a graduação em instituição pública (75\%); apresentava uma média de 4 anos e meio de experiência de trabalho e a Quase totalidade dos pesquisados tem título de especialização (90\%).

\section{Análise dos Depoimentos}

Tomando por base o problema de pesquisa, o objeto de estudo e as Questões norteadoras, e a partir da análise dos depoimentos e dos dados coletados no diário de campo, foi possível identificar as atividades Que caracterizam o fazer profissional dos enfermeiros, conhecer e analisar a metodologia assistencial utilizada para sistematizar suas ações em um hospital filantrópico e agrupá-los em três categorias: a) Fazer profissional do enfermeiro: fazer assistencial $x$ fazer administrativo; b) Metodologia assistencial: $o$ conhecimento direcionando à prática; 3) Sistematização da Assistência de Enfermagem (SAE) como metodologia.

\section{Fazer profissional do enfermeiro: fazer assistencial $\mathbf{x}$ fazer administrativo}

Os entrevistados relatam que o fazer assistencial do profissional enfermeiro caracteriza-se pela realização de procedimentos de maior complexidade técnica, de visitas de enfermagem e do cuidado com os pacientes mais graves. Nos depoimentos abaixo, é possível perceberem-se atividades Que caracterizam o fazer assistencial desses enfermeiros, Quando Questionados acerca das atividades realizadas em sua prática profissional:

[...] Só as atividades mais específicas do enfermeiro que é a passagem de sonda, Quando tem para passar, no caso de sonda vesical de demora, de alívio, nasogástrica e punção de cateter, Que tem haver com a oncologia em si. [...] (D5).

Na parte assistencial em si, sondagem, oxigenioterapia, todos esses procedimentos técnicos a gente acaba fazendo (D6).

As atividades assistenciais são as visitas de enfermagem, Que a gente realiza no leito do paciente e as práticas do enfermeiro, Que são a passagem de sonda [...] (D8).

A gente desenvolve atividades assistenciais, desde uma punção venosa, um cateterismo vesical, sonda nasogástrica, punção de cateter totalmente implantado, instalação de Quimioterápicos, [...] (DI0).
É possível encontrar também nos depoimentos coletados a definição dos enfermeiros Quanto ao fazer administrativo, descrito por eles como fazer burocrático:

As atividades burocráticas vão desde admissão de pacientes, fornecimento de leitos, encaminhamento de pacientes para exames e recebimento dos exames (D5).

Tem a parte burocrática, Que também a gente se envolve bastante como a organização de prontuários, liberação de exames, marcação de exames, tanto dentro do hospital Quanto fora do hospital (D7).

Alguns autores confirmam Que os enfermeiros têm assumido atividades assistenciais e administrativas em sua rotina de trabalho nos estabelecimentos de saúde. Entre as atividades assistenciais, relatam os cuidados com os pacientes mais graves e os procedimentos mais complexos. Em relação às atividades administrativas, descrevem aQuelas relacionadas à organização e à coordenação do serviço ${ }^{(10)}$. No entanto, percebeu-se em face das falas Que os enfermeiros encontram-se inseridos em uma rotina de trabalho e Que, apesar de fazerem separação entre atividades assistenciais e atividades administrativas não conseguem definir bem o seu papel Quanto ao fazer profissional, de caráter ora assistencial, ora administrativo.

Como bem destacam determinados autores, tem-se Que, predominantemente, o fazer administrativo do enfermeiro caracteriza-se não por atividades de gerenciamento da assistência de enfermagem, como preconizado na formação profissional, mas pelo gerenciamento do serviço, Que visa a facilitar o serviço de outros profissionais, principalmente com relação às condições necessárias para a realização das atividades médicas ${ }^{(1)}$.

\section{Metodologia Assistencial: o conhecimento direcionando à prática}

Ao serem indagados acerca da metodologia assistencial utilizada para sistematização de suas atividades, e com informações colhidas no diário de campo, pôde-se observar Que a Quase totalidade dos enfermeiros direciona sua atuação em função de prioridades, necessidades básicas, visão holística, resolutividade e motivos de internação, direcionados pelo conhecimento adeuirido na prática e na graduação, sem considerar metodologias preestabelecidas como base para suas ações e esboçam conhecimento acerca das teorias de enfermagem. No entanto, não a associam de forma consciente e programada à assistência prestada.

Há estudos Que confirmam essas opiniões, ao relatar Que os enfermeiros desenvolvem suas atividades empiricamente, como conseqüência da rotina de seu trabalho, sem nenhuma reflexão, utilizando, de forma inexpressiva, métodos em sua prática profissional $^{(3)}$. A não utilização de um referencial teórico na metodologia assistencial compromete a Qualidade da assistência prestada, promove a desorganização do serviço e desvalorização do profissional enfermeiro ${ }^{(12)}$.

Foi possível observar que um pequeno percentual dos enfermeiros entrevistados conhece as Teorias de Enfermagem, porém esse conhecimento é superficial, constituído apenas de pressupostos teóricos e conceitos sem muita consistência. 
Os depoimentos Que seguem demonstram a realidade citada:

A gente avalia o cliente, baseado na própria necessidade dele, dependendo da patologia que esse doente tenha, é que eu começo a sistematizar a minha assistência. Essa que é a da Wanda Horta não é? Das necessidades humanas básicas? (DI).

Eu sempre procuro pôr em prática o Que eu vi na faculdade. A parte dos métodos da Wanda Horta, a parte de ver sempre o paciente como um todo, para avaliar a sua necessidade prioritária e presto a assistência nesse sentido. [...] Eu tenho livros atuais e gosto de ler, gosto de ir-me atualizando, de ver o que sai de novo. Até porque eu acredito que fundamentando as nossas atividades, com a nossa prática assistencial a gente vai chegar longe, então é assim que eu procuro valorizar nossa profissão (D4).

Tem a da Dorotea Orem. Mas assim eu não sei te dizer assim com certeza qual eu sigo, tipo assim à risca, tem uma que eu ainda escolhi, Que sigo à risca, Que eu procuro fazer assim bem direitinho. Não. Tem uma teoria Que eu não lembro o nome agora, Que é justamente essa de ver o paciente como um todo, eu tento fazer assim (D6).

Eu, como enfermeira, aplico várias teorias, eu aplico a teoria do auto-cuidado, porQue quando eu estou cuidando de um paciente, Que tem colostomia, eu já vou ensinando para ele, orientando como é Que ele vai fazer em casa, Quando o paciente tem sonda nasoenteral, eu vou orientando a família como é que vai fazer, para não obstruir a sonda, não ter problemas, várias teorias você vai procurando. A teoria de Orem, Que é a teoria do auto-cuidado, e tem outras como Calixta Roy, de resolver o problema daquele paciente naquele momento. Quem tem o conhecimento das teorias sabe naquele momento Qual a teoria está aplicando (DI0).

A aplicabilidade das Teorias de Enfermagem na prática assistencial dos enfermeiros garante uma direção de como ver e prever os fatos, os eventos e suas articulações, o Que contribui para uma aproximação efetiva do contexto no Qual o enfermeiro irá desenvolver suas ações, orientando, portanto, as práticas de enfermagem ${ }^{(13)}$.

Vale ressaltar Que a utilização de um marco conceitual embasa as atividades realizadas, descaracteriza o tecnicismo e repetição de ações rotineiras, proporciona uma prática de enfermagem adeQuada às necessidades do cliente e configura segurança ao profissional enfermeiro ${ }^{(4)}$.

\section{Sistematização da Assistência de Enfermagem (SAE) como metodologia}

Ainda ante a indagação acerca da metodologia assistencial utilizada para sistematização de suas atividades práticas, e ante Questionamentos sobre a utilização da Sistematização da Assistência de Enfermagem (SAE) como metodologia, pôde-se perceber Que todos os entrevistados reconhecem a SAE. Alguns relatam a importância de sua aplicabilidade, embora não a utilizem em sua prática ou aplieuem de forma fragmentada, com predominância das seguintes fases: Histórico de Enfermagem e Evolução de Enfermagem.

Isso pode ser observado nos depoimentos a seguir:

Você pode utilizar, mas não por completo. Por exemplo: a SAE, você tem uma avaliação inicial do paciente, tem Que ter a entrevista, o exame clínico e a anamnese [...]. Depois disso, você vai para a fase Que seria a fase de diagnóstico, você vai diagnosticar, identificar e fazer as condutas de enfermagem (D2).

Confesso Que eu não uso SAE. Apesar de ter sido batido tanto na tecla enquanto acadêmica, todo mundo falando na $S A E$, mas eu confesso que eu não uso SAE. Sistematizar a minha assistência, não faço, confesso Que não faço, deveria fazer, mas não faço ainda (D6).

Há autores Que definem bem o Que expressam os depoentes. Dizem Que a grande maioria dos enfermeiros julga importante e percebe a necessidade de uma normatização de suas ações, entretanto, na prática, os métodos de assistência são utilizados de forma inexpressiva, Quando utilizada; apresenta-se de forma indefinida, dada as inúmeras dificuldades encontradas para sua operacionalização( ${ }^{(3)}$.

Das dificuldades encontradas para operacionalização da SAE, destacou-se a falta de tempo, em face do grande número de pacientes a serem assistidos e por ser considerada ainda processo muito burocrático.

A seguir depoimentos reveladores desse contexto:

A gente cuida de muitos pacientes, muitas crianças, são trinta crianças, então não é realizada a Sistematização da Assistência em si, mas assim é feito o histórico de enfermagem de todas essas crianças, Quando eu posso fazer eu faço, Quando eu não posso fazer as técnicas de enfermagem, elas fazem (D7).

Eu acho a SAE muito burocrática, é muito papel eu acho, então a gente precisaria de mais profissionais enfermeiros dentro do ambiente hospitalar para implementar a SAE (DII).

Autores de um estudo realizado no Ceará já afirmavam Que entre as dificuldades citadas para implementação da SAE, a maioria dos enfermeiros relata ter um conhecimento teórico reduzido sobre essa prática, além da sobrecarga com diversas tarefas, de Que resulta escassez de tempo para preenchimento dos papéis específicos de cada fase da referida metodologia de assistência ${ }^{(14)}$. Além disso, existe uma demanda muito grande de pacientes e escassez de recursos humanos, o Que sobrecarrega os profissionais e compromete a realização de cuidados sistematizados com os clientes $^{(15)}$.

Como destacado acima, grande parte dos entrevistados não aplica na íntegra a SAE. Aplica em sua assistência, de forma fragmentada e desarticulada, com maior freqüência o Histórico de Enfermagem e Evolução de Enfermagem, entretanto, mesmo assim, relatam Que não conseguem fazer o registro dessas atividades conforme preconiza a Resolução COFEN no 272/2002.

Nos depoimentos seguintes, constata-se isso: 
A gente não faz registros, mas a partir do momento Que você deixa subentendido, Que tem Que verificar os sinais vitais de um paciente de 6/6 horas, então você nem precisa prescrever, nem precisa dizer para o próximo plantonista enfermeiro Que vier, ele vai ter Que fazer isso (D5).

Então existem até algumas prescrições Que você faz, mas Que você faz assim, não sei nem se eu posso chamar de prescrição, é uma orientação, mas registro não é feito não. Quando dá, eu faço a evolução de enfermagem, mas todo dia eu pegar o paciente e fazer a evolução, não. PorQue são 50 pacientes (DI0).

A Enfermagem, com certa freeüência, não registra de modo sistemático e compreensível o cuidado Que foi realizado. Isso caracteriza a profissão como simplesmente a execução de tarefas manuais rotineiras, reveladoras de descomprometimento com a assistência prestada, o Que pode ser índice da falta de reconhecimento profissional e das dificuldades na avaliação de sua prática enQuanto profissional de saúde ${ }^{(1)}$.

\section{CONSIDERAÇÕES FINAIS}

Com a realização do estudo, pode-se considerar Que a prática profissional dos enfermeiros encontra-se predominantemente relacionada a um fazer assistencial e a um fazer administrativo. $\mathrm{O}$ fazer assistencial caracteriza-se em regra pela realização de procedimentos de maior complexidade técnica, e encontra-se inserido em um contexto definido por uma sobrecarga de trabalho e um tempo reduzido para execução de atividades. Assim, o foco prioritário, para a grande maioria deles, passa a ser a resolução de problemas, de Que decorre uma seleção de prioridades na assistência.

O fazer administrativo relaciona-se à organização e à coordenação de serviços e não à assistência de enfermagem. Isso produz uma descaracterização do enfermeiro, enQuanto cuidador. Observa-se Que o enfermeiro não consegue definir bem seu papel
Quanto a seu fazer profissional, sendo ora assistencial, ora administrativo, advindo daí conflitos pessoais.

Em relação à metodologia assistencial adotada para sistematização de ações, não há na prática a aplicação de um método preestabelecido. $\mathrm{O}$ Que direciona as ações dos enfermeiros é o atendimento prioritário das necessidades dos pacientes. Ocorre, portanto, uma adequação "inconsciente" de uma metodologia baseada no conhecimento adeuirido ao longo da sua formação e aplicado de acordo com as condições reais de trabalho, no caso, direcionada a voltada para atender às necessidades humanas básicas dos clientes.

A sobrecarga de trabalho e a necessidade de trabalho levam os enfermeiros a um distanciamento entre teoria e prática. Isso enseja preocupação Quanto à consolidação dos enfermeiros como profissionais autônomos, responsáveis por planejar a assistência de enfermagem, podendo restringir a sua atuação nas instituições de saúde.

A compreensão e o entendimento das atividades presentes na prática dos enfermeiros, Que caracterizam o fazer profissional, assim como da metodologia assistencial utilizada para sistematizar as ações, tornam-se ferramentas imprescindíveis para a eliminação dos problemas existentes. À luz desse raciocínio, promover-se-á uma melhor articulação entre os componentes da equipe de enfermagem, o Que favorecerá o reconhecimento pela equipe de saúde, instituição e principalmente pelo paciente, além de elevar a Qualidade e eficiência da assistência, bem como a valorização do profissional enfermeiro.

Espera-se que o estudo da prática profissional e da metodologia assistencial dos enfermeiros sirva como instrumento de avaliação do fazer profissional dos enfermeiros assistenciais, assim como seja uma recomendação para novos estudos na área pesquisada. Anseiase também Que as reflexões extraídas permitam implementar novos modelos de prática, embasados na normatização Que preconiza a SAE como modelo assistencial a ser adotado em todos os campos de assistência à saúde pelo enfermeiro.

\section{REFERÊNCIAS}

I. Garcia TR, Nóbrega MML. Sistematização da assistência de enfermagem: reflexões sobre o processo. In: Anais do $52^{\circ}$ Congresso Brasileiro de Enfermagem. 2000; Recife/Olinda (PE), Brasil. Recife (PE): Aben-PE; 2000.

2. Cianciarullo TI, Gualda DMR, Melleiro MM Anabuki MH. Sistema de assistência de enfermagem: evolução e tendências. São Paulo (SP): Ícone; 2001

3. Thomaz VA, Guidardello EB. Sistematização da assistência de enfermagem: problemas identificados pelos enfermeiros. Nursing 2002; 18(4): 28-34

4. Westphalen MEA, Carraro TE. Metodologia para a assistência de enfermagem: teorizações, modelos e subsídios para a prática. Goiânia (GO): AB; 2001 .

5. Fernandes MS. A função do enfermeiro nos anos 90: réplica de um estudo [dissertação]. Ribeirão Preto (SP): Escola de Enfermagem de Ribeirão Preto. Universidade de São Paulo; 2000.

6. Santos IE. Manual de métodos e técnicas de pesquisa científica: tcc, monografia, dissertação e tese. Rio de Janeiro (RJ): Impetus; 2005.

7. Minayo MCS. Pesquisa social: teoria, método e criatividade. Petrópolis (RJ): Vozes; 2000.

8. Ministério da Saúde (BR). Conselho Nacional de Saúde. Diretrizes e normas regulamentadoras da pesQuisa envolvendo seres humanos: Resolução no 196/96. Brasília (DF): Ministério da Saúde; 1996.

9. Lobiondo-Wood G, Haber I. Pesquisa em enfermagem: métodos, avaliação crítica e utilização. $4^{a}$ ed. Rio de Janeiro (RI): Guanabara Koogan; 2001.

10. Costa RA, Shimizu HE. Estudo das atividades desenvolvidas pelos enfermeiros em um hospital-escola. Rev Esc Enferm USP 2006; 40(3): 418-26.

I1. Faveri F, Fernandes MS. Função administrativa do enfermeiro: administração da assistência ou administração dos serviços? Rev Enferm Atual 2003; 18(3):32-6. 
12. Andrade IS, Vieira MI. Prática assistencial de enfermagem: problemas, perspectivas e necessidade de sistematização. Rev Bras Enferm 2005; 58(3): 26I-69.

13. Wernet M, Oliveira APZ. Articulando o modelo de adaptação de Roy aos adolescentes portadores de sarcomas ósseos. Nursing 2003; 61 (6): 14-9.

14. Feijão AR, Carvalho MF, Carmo FT, Brito DMS, Galvão MTG.
Avaliação da sistematização da assistência de enfermagem em hospital de doenças infecciosas. Online Braz I Nurs 2006; 5(2): $1-10$.

15. Melo EL, Vilarinho LM, Vasconcelos FBM, Lúcio, IA. Vivência dos discentes na implementação da SAE em um hospital escola no estado do Piauí. Anais do $3^{\circ}$ Congresso de Enfermagem do Piauí; 2007; Teresina (PI), Brasil. Teresina (PI): ABEn-PI; 2007. p. I-I 5. 